\title{
Saúde mental infantojuvenil e desafios do campo: reflexóes a partir do percurso histórico ${ }^{1}$
}

\author{
Bruna Lidia Tańo ${ }^{a}$, Thelma Simóes Matsukura ${ }^{\mathrm{a}, \mathrm{b}}$ \\ aPrograma de Pós-Graduação em Educação Especial, Universidade Federal de São Carlos - UFSCar, \\ São Carlos, SP, Brasil. \\ bPrograma de Pós-Graduação em Terapia Ocupacional, Universidade Federal de São Carlos - UFSCar, \\ São Carlos, SP, Brasil.
}

\begin{abstract}
Resumo: Por meio de uma revisão de obras e estudos de referência sobre o tema, este texto reflexivo tem como objetivo discutir o campo da saúde mental infantojuvenil no Brasil, abarcando seu processo de constituição até o momento atual. Para tanto enfoca o desenvolvimento inicial do campo fundado a princípio na psiquiatria infantil; apresenta considerações a respeito da relevância do movimento da Reforma Psiquiátrica e delineia as atuais políticas de saúde mental para esse grupo. Busca problematizar os modos com que atualmente tem sido realizada a atenção em saúde mental para crianças e adolescentes que se encontram em experiência de sofrimento psíquico, principalmente para aqueles que se encontram em situação de maior gravidade. Sugere-se que as políticas e ações de cuidado a serem estabelecidas possam sanar uma dívida histórica no que tange à resposta e ao cuidado das questões de maior complexidade colocadas pelas situações de sofrimento que impedem o exercício da autonomia para essas crianças e adolescentes.
\end{abstract}

Palavras-chave: Saúde Mental, Politicas Públicas, Criança, Adolescente.

\section{Child and adolescent mental health and field challenges: reflections from the historical path}

\begin{abstract}
By means of a review of reference works and studies on the theme, this reflective text aims to discuss the field of Child and Adolescent Mental Health in Brazil, covering its constitution process until the present time. To this end, it focuses on the initial development of the field, originally established in Child Psychiatry, presents considerations regarding the relevance of the Psychiatric Reform, and outlines the current mental health policies for this specific group. It aims to raise questions on the ways in which mental health care has been currently performed for children and adolescents who find themselves in psychic suffering, especially for those who are in more serious situations. It is suggested that policies and actions of caring to be established may remedy a historical debt on the response and care of more complex issues raised by situations of suffering that prevent the exercise of autonomy for children and adolescents.
\end{abstract}

Keywords: Mental Health, Public Policies, Children, Adolescent.

Autor para correspondência: Bruna Lidia Taño, Programa de Pós-Graduação em Terapia Ocupacional, Universidade Federal de São Carlos, Rodovia Washington Luis, Km 235, Monjolinho, CEP 13565-905, São Carlos, SP, Brasil, e-mail: bruna.tano@yahoo.com.br

Recebido em Out. 12, 2013; $1^{\text {a }}$ Revisão em Jun. 24, 2014; $2^{\mathrm{a}}$ Revisão em Fev. 9, 2015; Aceito em Mar. 11, 2015. 


\section{Introdução}

A política de saúde mental no SUS e sua recente reformulação por meio da construção das Redes de Atenção Psicossocial - RAPS revelam no campo $\mathrm{da}$ atenção às crianças e adolescentes uma dívida de cuidado para estes sujeitos (COUTO, 2001; BRASIL, 2011, 2013). As novas proposiçóes nesta esfera buscam permitir o redimensionamento da experiência de sofrimento psíquico em sua relação com a sociedade por meio da criação e instalação de diferentes mecanismos de cuidados. Neste panorama, incluem-se os Centros de Atençâo Psicossocial Infantojuvenis destinados principalmente para as crianças e adolescentes em sofrimento psíquico intenso (BRASIL, 2004, 2011).

Ainda que estes serviços tenham como premissa o atendimento à população infantojuvenil mais gravemente comprometida, estudos recentes têm indicado importantes dificuldades e barreiras para o acesso e permanência destes sujeitos no cotidiano dos locais de atendimento (BLIKSTEIN, 2012; FERNANDES, 2014; TAÑO, 2014).

Entende-se que parte dessa dificuldade de cuidado tem suas causas também decorrentes dos processos históricos de atenção à saúde mental infantojuvenil no país, que foram constituídos ao longo das décadas. Sobre esse aspecto, realizar uma retomada desses processos à luz das políticas atuais pode fornecer pistas para pensar a superação de desafios e problemáticas assinaladas na prática do cuidado com esses sujeitos.

Por meio de uma revisão bibliográfica assistemática e estudos de referência sobre o tema, este texto reflexivo teve como objetivo discutir o campo da saúde mental infantojuvenil no Brasil, abarcando seu processo de constituiçáa até o desenvolvimento atual das políticas públicas para esse público.

\section{Percurso histórico da saúde mental infantojuvenil}

O caminho trilhado no campo da atenção à saúde mental das crianças e adolescentes ao longo do tempo, a despeito da história da saúde mental do adulto, conheceu movimentos diferentes, no que se refere aos projetos políticos e ao contexto de interesses e premissas colocados para sua consolidação (COUTO, 2001).

No cenário internacional e com importantes repercussões no Brasil, as bases teóricas da psicopatologia da infância e adolescência derivavam-se de duas correntes principais, uma que transpunha para este grupo populacional as mesmas considerações sobre a psicopatologia do adulto, no chamado adultomorfismo (REIS et al., 2010), e outra, que se detinha pela descrição dos processos de incapacidade e deficiências intelectuais. Em relação aos adolescentes, que não constituíam alvo das políticas para educação formal, delineia-se o construto do jovem delinquente (RIBEIRO, 2006). Além da categorização psicopatológica da delinquência, referiam-se como diagnósticos próprios das crianças e adolescentes a idiotia, a debilidade e a imbecilidade (REIS et al., 2010; COUTO, 2001; RIBEIRO, 2006).

Em 1943, com a publicação de um estudo descritivo do funcionamento de uma criança autista por Leo Kanner nos Estados Unidos da América, efetiva-se uma ruptura fundamental na constituiçáo do campo da psicopatologia da infância e adolescência, inaugurando de forma mais precisa a Psiquiatria Infantil. Em seu estudo, Kanner se detém ao detalhamento de uma problemática eminentemente infantil, considerando que as crianças não possuíam os mesmos modos de funcionamento afetivo e psicológicos que os adultos. Sua importância decorre também de que Kanner se propóe à descrição de um acometimento grave, de ordem afetiva e não necessariamente intelectual (REIS et al., 2010).

Embora tenha se constituído com algumas similitudes aos processos de formação internacionais, as bases da psiquiatria infantojuvenil no Brasil serviram a outros projetos de saúde e de sociedade. Durante o período colonial, são escassas as referências a qualquer modalidade de atenção à infância e adolescência. As primeiras ações destinadas à saúde mental infantojuvenil surgem conjuntamente com as primeiras iniciativas neste campo para os adultos, justamente com a inauguração do primeiro hospital psiquiátrico do país, em 1832, o Hospital D. Pedro II, no Rio de Janeiro. Neste período, e em decorrência de tal inauguração, foram realizados os primeiros estudos e teses brasileiros no campo da psiquiatria (COSTA, 1983; RIBEIRO, 2006).

O que se percebe é que as açôes à saúde das crianças e adolescentes, incluídos também os aspectos relativos à saúde mental, acompanharam o plano político, ideológico e social do país, após sua independência. Quanto mais a "cientifização" da disciplina médica tornava-se entidade reguladora dos modos de vida nas cidades, mais funcionava como aliada de uma burguesia urbana, que tinha entre seus projetos a negação do estilo de vida patriarcal de base rural, estabelecido durante o período do Brasil Colônia. Neste plano, o controle das situaçóes de precariedade foi impulsionado pelo discurso do Movimento Higienista, que embora não tenha 
tido grande representatividade numérica entre a sociedade, e tampouco participação popular em suas formulações, foi responsável por estabelecer uma série de prerrogativas em relação aos modos saudáveis de vida e convivência nas cidades que se estabelecem ainda hoje (BOARINI; YAMAMOTO, 2004; REIS et al., 2010; RIBEIRO, 2006).

Surgem neste cenário, de modo mais sistematizado, as primeiras práticas direcionadas às crianças, incluindo as açôes ao cuidado materno-infantil. Os propósitos de higienização da sociedade encontravam nas crianças terreno fértil para seu desenvolvimento a partir da individualização das mazelas e responsabilidade sobre a saúde, produzindo-se uma série de indicaçôes e programas a serem executados no interior das escolas e educandários (RIBEIRO, 2006).

Neste panorama, tal como apontam Boarini e Yamamoto (2004), algumas das práticas difundidas pelo Movimento Higienista atrelam-se às condutas cunhadas e defendidas pelo Movimento Eugenista, que consistia em defender o melhoramento da raça. Esse melhoramento referia-se ao controle dos matrimônios e à reprovação de práticas e condutasde âmbito pessoal e familiar .

Cabe ressaltar que, embora os dois citados movimentos tenham tido importante repercussão na condução dos valores morais da sociedade burguesa no Brasil, ambos provinham, a princípio, da iniciativa privada e não contavam com recursos públicos nem se constituíam como política de Estado. Apesar disso, mesmo não figurando como política pública, assumiram expressiva relevância para os planos políticos de desenvolvimento e progresso nacional, cunhados especialmente em práticas de controle (BOARINI; YAMAMOTO, 2004).

Em meados da década de 1920, com a criação da Liga da Higiene Mental, entidade assumidamente preocupada com o desenvolvimento mental da população brasileira, em especial da infância, são desenvolvidas por esta açóes de assistência, frequentemente de caráter repressivo, em que as instituiçóes psiquiátricas de internação respondiam pelo papel de reguladoras do espaço social, dando possibilidades para o efetivo estabelecimento da disciplina psiquiátrica infantil, que, entre seus atributos, ocupava-se também de projetos de prevenção de patologias. Ao atuarem junto às crianças, e com forte veiculaçáo entre a população, atingiam também a organização das famílias brasileiras, entre outras coisas, incutindo nestas a ideia de que somente a disciplina médica seria capaz de orientar efetiva e adequadamente quanto aos modos de educação das crianças para uma vida saudável, afastada de insanidade, desvios de conduta e, principalmente, da delinquência (BOARINI; YAMAMOTO, 2004; REIS et al., 2010).

Os objetivos da psiquiatria infantil no território nacional residiam em sanar as problemáticas que caracterizavam o país enquanto nação atrasada como a delinquência e a mortalidade infantil, a partir da moralização da sociedade e do controle de suas condutas. Surgem com esta finalidade as primeiras clínicas de orientação infantil, principalmente nas cidades de São Paulo, Rio de Janeiro e Belo Horizonte, que além de médicos psiquiatras e pediatras contavam também com a chegada recente de psicólogos e psicanalistas, que atuavam também com foco nas problemáticas relacionadas aos processos de aprendizagem (BOARINI; YAMAMOTO, 2004; RIBEIRO, 2006).

Por outro lado, as crianças e adolescentes severamente comprometidos em decorrência do sofrimento psíquico mantinham-se reclusas em alas conjuntas com os adultos nos hospitais psiquiátricos do país. Uma vez que as principais ações no campo da saúde mental infantojuvenil se detinham à prevenção de agravos, poucas açôes estiveram descritas e direcionadas às populaçóes em intenso sofrimento psíquico. À exceção de tal constataçáo tem-se, em 1902, a criação do Pavilhão Infantil anexo ao Hospital da Praia Vermelha no Rio de Janeiro, e da Ala Infantil no Hospital Juqueri, em 1921, em São Paulo (RIBEIRO, 2006).

A principal forma de institucionalizaçáo de crianças e adolescentes em sofrimento psíquico se deu para além das instituições psiquiátricas, e deste fato advém a escassez de registros sobre o tema na área da saúde. Grande parte das crianças adoecidas permanecia em instituiçóes assistenciais mantidas por entidades filantrópicas, que, embora não figurassem nas comunidades psiquiátricas, mantinham modos de exclusão e violência muito semelhantes. As intervenções para institucionalização de crianças e adolescentes no Brasil foram utilizadas em proporções arrebatadoras. Durante décadas, esta foi a principal resposta para a maioria das problemáticas sociais. Assim, além das crianças e adolescentes com algum tipo de sofrimento psíquico, as crianças e adolescentes pobres também tiveram como alternativa única para sua existência a institucionalização. $\mathrm{O}$ medo social em relação ao louco e ao pobre, que supostamente poderia se tornar delinquente, justificou ao longo dos anos série de violaçôes à vida humana e à sua integridade (COUTO, 2001; COUTO; DUARTE; DELGADO, 2008; RIZZINI, 2005).

Em 1927, a criação do primeiro Código Melo de Mattos conferiu respaldo tanto às açóes em saúde 
mental já realizadas, como também à questáo da delinquência. No início da década de 1940, com a emergência do Estado Novo e sob a rubrica de seus projetos de nação, foi criado o Departamento Nacional da Criança, que inaugurou serviços estatais, públicos para a atenção à saúde mental de crianças e adolescentes. Desde o fim da década de 1970, o panorama de atenção se modificou pouco, à exceção da criação de algumas redes filantrópicas de atendimento à criança e ao adolescente com deficiência (REIS et al., 2010).

Mesmo que as políticas de saúde não tivessem contemplado as crianças e adolescentes no campo da saúde mental, outros documentos e políticas sociais deste período tiveram importantes repercussóes para a vida destes sujeitos. A exemplo, o Código de Menores de 1979 justificou internaçôes na Fundaçáo para o Bem-Estar do Menor (Febem) em quantidades abusivas cunhadas na ideia de uma suposta proteção aos riscos e perigos vividos pela população infantojuvenil. Estas internações, em sua maioria destinadas aos grupos populacionais mais pobres e em maior situação de vulnerabilidade, tiveram violentas repercussóes para o desenvolvimento e a vida de crianças e adolescentes, incluídas nestas o número aumentado de agravos de saúde mental (BRASIL, 2014).

A assistência à infância e adolescência no Brasil, tal como assinalado anteriormente, esteve marcada então por açôes de proteçấo que culminaram em reclusão e institucionalização com evidentes situações de privação de direitos e liberdade. Instituiçóes filantrópicas eram as principais responsáveis pelo cuidado que além de açôes restritivas continham forte apelo jurídico (COUTO, 2001; HOFFMANN; SANTOS; MOTA, 2008).

Parte do que se traduzia nestas açóes derivava de uma concepçáo sobre estas fases da vida humana que recusavam o transtorno mental infantil enquanto uma condição de existência. Os eventos de sofrimento e adoecimento psíquicos eram atravessados por diagnósticos de deficiência mental, que, outrossim, necessitavam de reparação e demandavam, para seu cuidado, práticas de caráter pedagogizante e adaptativo, negligenciando, destarte, as dimensóes subjetivas e até mesmo sociais da experiência de sofrimento. Grande parte das açôes em psiquiatria infantojuvenil se direcionava, por conseguinte, ao diagnóstico e intervenção nos déficits de aprendizagem e ao distúrbio de conduta (COUTO, 2001; REIS et al., 2010).

\section{Reabilitação psicossocial e reforma psiquiátrica: transformação dos paradigmas de atenção}

As iniciativas de questionamento da ordem de estruturação, organização e produção do conhecimento no campo da psiquiatria e da saúde mental no país, vigentes durante os séculos XIX e boa parte do século XX, tiveram como disparador inicial as produçôes das teses de Michel Foucault, A História da Loucura, e de Erving Goffman, Manicômios, Prisôes e Conventos, ambas datadas do final da década de 1960 (MÂNGIA; NICÁCIO, 2001; OLIVEIRA et al., 2012).

Conjuntamente com estes aportes teóricos, as experiências de transformação da atenção à saúde mental, produzidas coletivamente na Itália nas décadas de 1960 e 1970, tiveram repercussóes mundiais e também no Brasil, principalmente a partir das produçóes de Franco Basaglia, Franca O. Basaglia, e Franco Rotelli, que compuseram, com suas contribuiçóes teórico-práticas, o quadro referencial da Reabilitação Psicossocial (MÂNGIA; NICÁCIO, 2001).

As principais proposições da Reabilitação Psicossocial tiveram eco em inúmeros países e se fundamentaram essencialmente no entendimento de que a loucura é um problema também social e que, portanto, a partir desta condiçáo deve ser complexificada. As ideias-conceitos-operadores desta ação de cuidado em saúde questionam desde os modos com os quais se produziu historicamente o conceito de doença mental e as intervençóes destinadas a esta população, como também a forma com as quais se produzem as disciplinas que atuam neste campo (AMARANTE, 2007; PITTA, 2001). Salienta-se que, na atualidade, as consideraçôes da Reabilitação Psicossocial compóem parte das políticas e açôes em saúde mental, e formam parte das recomendaçóes realizadas pela Organização Mundial da Saúde para a construção de planos de atenção neste campo (ORGANIZAÇÃO..., 2001).

No Brasil, a crítica às práticas das instituiçôes asilares encontrou ressonância e motivação aliada aos movimentos de redemocratização do país, assim como nos primeiros movimentos que posteriormente resultaram na Reforma Sanitária (BALLARIN; CARVALHO, 2007).

Durante meados da década de 1970, as manifestaçôes frente aos abusos cometidos nos hospitais psiquiátricos do país foram tomando maiores dimensóes, quando 
então novas alternativas para o cuidado em saúde mental começaram a ser formuladas. Tal conjuntura possibilitou que as transformaçôes na assistência à saúde mental tivessem importante repercussão nas formulaçóes políticas da época e que fossem asseguradas tanto na promulgação da Constituição de 1988 como também na criação do Sistema Único de Saúde (SUS), no mesmo ano. As prerrogativas colocadas pelo movimento da Reabilitação Psicossocial inspiraram parte das políticas de saúde mental nacionais, culminando com a implantação da Lei n. 10.216 de 2001 (BRASIL, 2001), referência normativa ainda na atualidade, que estabeleceu a gradativa diminuição das internações em hospitais psiquiátricos destinadas apenas para situaçôes de excepcionalidade, e propôs a criaçáo de serviços territoriais de base comunitária para a atenção às pessoas em intenso sofrimento psíquico, os Centros de Atenção Psicossocial - CAPS (AMARANTE, 2007; BRASIL, 2004; MÂNGIA; NICÁCIO, 2001; PITTA, 2001).

Especificamente para as crianças e adolescentes em situação de sofrimento psíquico intenso, foram criados os CAPS infantojuvenis como recursos prioritários para o atendimento destas situaçóes, mais claramente especificados pelo Ato Portaria n. 185 de julho de 2003 (BRASIL, 2003).

Ainda que o movimento da Reforma Psiquiátrica, conjuntamente com outros marcos importantes para a defesa dos direitos de crianças e adolescentes, entre esses a promulgaçáo do Estatuto da Criança e do Adolescente em 1990 (BRASIL, 1995), tenha assinalado a importância do cuidado com estes sujeitos, observa-se que as açóes destinadas a estes grupos estiveram em segundo plano, quando comparado ao que se discutiu e propôs como estratégias de cuidado para os adultos em condições semelhantes de sofrimento psíquico (TAÑO, 2014).

A partir de 2011, por meio do Decreto/Portaria n. 3.088 (BRASIL, 2011), a atenção em saúde mental no Sistema Único de Saúde (SUS) ganha importantes reforços para sua ampliação e consolidação no âmbito territorial. A se somarem aos CAPS, outros pontos de atenção ganham relevância, para a constituição de uma rede efetiva de cuidados. Esta rede de cuidados se se compóe de diferentes pontos de atenção desde a Atenção Básica a Estratégias de Geração de Renda, Desinstitucionalização e Acolhimento Residencial. Fica determinado que, ainda que os CAPS se constituam como serviços especializados e destinados aos sujeitos em maior intensidade de sofrimento e oferececendo suporte técnico para outros serviços, os outros componentes devem produzir o cuidado preconizando a participação dos sujeitos nos diferentes contextos da vida social como educação, trabalho e lazer. Ressalta-se a relevância dos pontos da Atenção Básica, como principais responsáveis pela condução da gestão do cuidado das pessoas que se encontram em determinado território (BRASIL, 2011).

Embora a Reforma Psiquiátrica Brasileira tenha trazido importantes considerações e transformações ao modelo de atenção vigente, foi com mais lentidão que as políticas de saúde mental infantojuvenil se fizeram presentes, pois, mesmo que realizando importantes críticas aos modelos anteriores, as açôes concretas se mantinham em certo descompasso. Apesar das relevantes transformaçóes no campo da legislação a essas populaçóes ocorridas na década de 1990, entre elas o Estatuto da Criança e do Adolescente, percebe-se que estes novos modos propostos para o encontro com estes indivíduos, enquanto sujeitos de direito e assegurados para o pleno acesso em relação as suas demandas essenciais como saúde, educação, lazer, moradia, convivência familiar, encontraram dificuldades de execução em iniciativas concretas para esta população (COUTO, 2001).

\section{Atenção à saúde mental infantojuvenil atual: a luta pela ampliação do cuidado}

No atual panorama, as políticas de saúde e as ações de assistência social têm visado diminuir os processos de institucionalização das crianças e adolescentes, principalmente por meio do direito à convivência em família e na comunidade. Estas açóes têm o sentido de produzir efeitos contrários ao que se vinha estabelecendo historicamente. Trata-se, sobretudo, em restituir, também para este grupo, a capacidade contratual que lhes é a expressão da cidadania.

Em levantamento bibliográfico realizado por Cunha e Boarini (2011), a partir da análise de publicaçóes científicas e digitalizadas com o tema principal CAPSi, os resultados apontaram que ainda persiste um descompasso entre o que preconiza a política pública e o que é realizado nos serviços no que tange à população atendida. As produçóes encontradas relatam experiências clínicas e comunitárias que se dão com crianças e adolescentes que aparentemente não circulam entre as chaves diagnósticas tidas como gravemente comprometidas - autismos e psicoses têm causado importante desamparo à populaçáo em franco sofrimento e com poucas outras possibilidades de inserção em espaços comuns. Já Bueno (2013), ao caracterizar o trabalho dos terapeutas ocupacionais que atuam nos Centros de Atenção Psicossocial 
Infantojuvenis, apresenta as mesmas consideraçóes ao afirmar que a população que mais acessa o serviço, em totalidade de atendimentos, náo é a população prioritariamente descrita na política de saúde mental infantojuvenil (crianças e adolescentes com prejuízos severos).

Outros estudos vêm ainda apontando as dificuldades de constituição de uma rede de atenção em saúde mental que possa efetivamente constituir ampliação da contratualidade, exercício de cidadania e proteção para crianças e adolescentes no Brasil. A esse respeito, Blikstein (2012), por meio da análise de prontuários de hospital de referência para internação de crianças e adolescentes no Estado de Sáo Paulo, identificou que ainda se observa um importante número de internaçôes e reinternaçôes de crianças e adolescentes decorrentes de processos judiciais e de encaminhamentos de serviços de saúde. O número de solicitaçôes e de encaminhamentos para internação provenientes de serviços de saúde territoriais é bem próximo ao número dos pedidos judiciais realizados. A análise, que se deteve aos anos de 2005 a 2009, revelou ainda que a maioria dos internados são de adolescentes do sexo masculino, como também esclarece quanto ao número expressivo de casos de reinternação. A respeito do diagnóstico que mais teve ocorrência nos casos em estudo aparecem em primeiro lugar os diagnósticos de esquizofrenia e correlatos seguidos pelos transtornos de humor.

A respeito das práticas de apoio entre serviços, estudo realizado por Cavalcanti, Jorge e Santos (2012) indicou que as açóes de matriciamento realizadas entre equipes de Estratégia de Saúde da Família (ESF) e equipes especializadas de saúde mental (CAPS) do município de Fortaleza (CE) náo contemplaram a discussão de casos abordando crianças ou adolescentes em sofrimento psíquico. As autoras acrescentam ainda que problemas na consolidação das redes de atenção em saúde mental infantojuvenil; a dificuldade dos profissionais em lidarem com este campo de atuação, a dificuldade dos familiares em tratarem do assunto por medo de exposiçáo e a invisibilidade do sofrimento de crianças e adolescentes podem ser possíveis causas desta situação. Neste tema, Delfini e Reis (2012), em estudo no município de São Paulo, também reconhecem que ainda que sejam assinaladas ações de discussão de casos e de matriciamento entre ESF's e os CAPSi, a desresponsabilização pelo cuidado e a falta de capacitação profissional são desafios para a atenção à crianças e adolescentes em sofrimento.

Os esforços realizados para a inserção de crianças e adolescentes em intenso sofrimento nos serviços territoriais se constituem enquanto desafio
(COUTO; DELGADO, 2010; FERNANDES, 2014; TAÑO, 2014), que encontra, portanto, dificuldades fundamentais para sua realização, assim como pôde ser observado nos diferentes estudos apresentados.

Quanto ao funcionamento dos serviços prioritários para atendimento desta população - os CAPSi -, outros estudos têm apontado que há uma tendência em ocupação destes espaços por crianças e adolescentes com outras queixas e problemáticas. As condutas de psiquiatrização e psicologização da infância e adolescência, principalmente no que tange aos problemas de aprendizagem e dos inumeráveis transtornos de conduta, superlotam os CAPSi e em geral produzem mais ruído que os sofrimentos intensos de ordem psíquica ${ }^{2}$ (AMSTALDEN; HOFFMAN; MONTEIRO, 2010; BRASIL, 2005; COUTO; DELGADO, 2010).

Os CAPSi detêm a potência para a produção de relações de cuidado cunhadas na emancipação dos sujeitos, mesmo daqueles que por vezes se mostram em intensas dificuldades (ELIA, 2005). Sua função organizadora pode residir na capacidade de produzir cidadania para as crianças e adolescentes muitas vezes afastadas de outros locais de sociabilidade. Impóe-se a tarefa de fazer crescer os locais de vida desta populaçáo, a partir primeiramente da complexificação dos modos pelos quais os grupos acessam e permanecem nos serviços e pelas práticas exercidas nos CAPSi.

Os atuais avanços na proposição de novas estratégias em cuidado em saúde mental, ainda que tenham considerado a complexidade da construção de açóes para as crianças e adolescentes (BRASIL, 2011), enfrentam o desafio de poder fazer funcionar a atenção aos grupos dos quais historicamente se manteve alijada. Proporcionar espaços de cuidado para os sujeitos em condiçôes delirantes, em percursos de sofrimento pouco compartilhados e ainda assim garantir suas possibilidades de participação social, educação, moradia e cidadania são respostas necessárias para o avanço do cuidado. Para este caminho, açóes que contemplem arranjos intersetoriais, atendimentos familiares e a construção do controle social efetivo nos serviços podem produzir de fato a transformação necessária que assegure a devida inserção e cuidado das crianças e adolescentes que sofrem (TAÑO, 2014).

Ao que se aponta, avaliar e problematizar, em sentidos mais profundos e amplos, os modos com os quais historicamente se produziu o encontro com as crianças pode oferecer ferramentas para a decisão sobre os caminhos mais potentes a serem percorridos. Evidencia-se que os principais problemas descritos na atualidade, entendidos enquanto desafios para 
a construção do cuidado neste campo, referem-se substancialmente a situaçôes historicamente presentes, embora trajando novas roupagens: a psiquiatrização da demanda escolar, a patologização dos casos então considerados desvios de conduta; a ausência de planos mais elaborados para os casos mais graves; bem como as atuais políticas e programas para o enfrentamento do uso de drogas (AMSTALDEN; HOFFMANN; MONTEIRO, 2010; BRASIL, 2005, 2013).

\section{Da política ao possível: considerações finais}

O que se evidencia, a partir do exposto, é que as práticas realizadas no campo da saúde mental infantojuvenil para aqueles que se encontram em situação de intenso sofrimento parecem ainda bastante prejudicadas. Embora os CAPSi figurem como ponto de atençáo prioritário para estes sujeitos, permanecem fragilidades na garantia do cuidado que repercutem imediatamente na impossibilidade de uma atenção mais aproximada e efetiva.

A discussão sobre o acesso de crianças e adolescentes no cotidiano dos serviços e, mais do que isso, o fortalecimento de sua possibilidade de continuidade no acompanhamento são questóes prioritárias que necessitam estar presentes na realidade dos equipamentos, como também descritas na produção de conhecimento na área.

O enfoque histórico nos processos de constituiçáo e de afirmação de uma rede de cuidados para crianças e adolescentes em sofrimento psíquico permitiu que se evidenciassem as características e influências dos movimentos de cuidado realizados na atualidade. Neste caminho, indicar o passado das açôes para este grupo revelou que os impasses atuais são também manifestaçóes de problemas e processos para os quais historicamente foram dedicadas açôes punitivas, restritivas e nada resolutivas. Ainda que o movimento atual esteja afinado ao direito das crianças e adolescentes, evidenciou-se por meio dos estudos apresentados que desafios contemporâneos como o cuidado nas situaçôes de uso de substâncias psicoativas, o manejo e a inclusão das pessoas com transtornos do espectro do autismo, e os números ainda alarmantes de internaçôes psiquiátricas, parecem resultado do que se construiu como prática de assistência durante décadas.

Assim, depreende-se que dentre os processos de transformação da lógica da atenção em saúde mental para a infância e adolescência, se faz importante o esforço em conhecer, avaliar e descrever como têm sido efetivadas as transformaçóes que constam nos documentos e nas práticas. Deste modo, considerar crianças e adolescentes não apenas como parte de projetos político-ideológicos a serem colocados em marcha no território, mas sim que possam ser reconhecidas e encontrar espaços de cuidado e de atenção que promovam a saúde, a autonomia e o aumento da participação social, deve ser a ação principal a ser empreendida por profissionais, gestores e sociedade. Fazer, portanto, aproximar as políticas à vida comunitária e aos serviços que, localizados nos territórios, têm a responsabilidade concreta pela transformação das relaçóes entre os processos de saúde e doença de crianças e adolescentes, e suas possibilidades de exercício de ampliação de vida e de condiçóes de construçóes de experiências mais coletivas e emancipatórias.

\section{Referências}

AMARANTE, P. Saúde mental e atençāo psicossocial. Rio de Janeiro: Fiocruz, 2007.

AMSTALDEN, A. L. F.; HOFFMANN, M. C. C. L.; MONTEIRO, T. P. M. A política de saúde mental infanto-juvenil: seus percursos e desafios In: LAURIDSENRIBEIRO, E. P. P.; TANAKA, O. Y. (Org.). Atenção em saúde mental para crianças e adolescentes no SUS. São Paulo: HUCITEC, 2010. p. 33-45.

BALLARIN, M. L. G. S.; CARVALHO, F. B. Consideraçóes acerca da Reabilitação Psicossocial: aspectos históricos, perspectivas e experiências. In: CAVALCANTI, A.; GALVĀO, C. Terapia Ocupacional: fundamentação e prática. Rio de Janeiro: Guanabara Koogan, 2007. p. 162-170.

BLIKSTEIN, F. Destino de crianças: estudo sobre internaçôes de crianças e adolescentes em Hospital Público Psiquiátrico. 2012. 91 f. Dissertação (Mestrado em Psicologia Social)-Pontifícia Universidade Católica de São Paulo, São Paulo, 2012.

BOARINI, M. L.; YAMAMOTO, O. H. Higienismo e Eugenia: discursos que não envelhecem. Psicologia em Revista, Belo Horizonte, v. 13, n. 1, p. 59-72, 2004. Disponível em: <http://www.cocsite.coc.fiocruz.br/psi/ pdf/higienismo_eugenia.pdf >. Acesso em: 30 jul. 2012.

BRASIL. Estatuto da Criança e do Adolescente. 5. ed. São Paulo: Saraiva, 1995.

BRASIL. Lei no 10.216 de 6 de abril de 2001. Dispõe sobre a proteçáo e os direitos das pessoas portadoras de transtornos mentais e redireciona o modelo assistencial em saúde mental. Diário Oficial da União, Poder Executivo, Brasília, DF, 9 abr. 2001.

BRASIL. Ministério da Saúde. Secretaria de Assistência à Saúde. Portaria SAS no 185 de 10 de julho de 2003. Diário Oficial da União, Poder Executivo, Brasília, DF, 11 jul. 2003.

BRASIL. Ministério da Saúde. Secretaria de Atenção à Saúde. Departamento de Ações Programáticas Estratégicas. 
Saúde mental no SUS: os centros de atenção psicossocial. Brasília, 2004.

BRASIL. Ministério da Saúde. Secretaria de Atenção à Saúde. Departamento de Açôes Programáticas Estratégicas. Caminhos para uma politica de saúde mental infanto-juvenil. Brasília, 2005.

BRASIL. Ministério da Saúde. Portaria no 3.088 de 23 de dezembro de 2011. Institui a Rede de Atenção Psicossocial para pessoas com sofrimento ou transtorno mental e com necessidades decorrentes do uso de crack, álcool e outras drogas, no âmbito do Sistema Único de Saúde (SUS). Diário Oficial da União, Poder Executivo, Brasília, DF, 26 dez. 2011.

BRASIL. Ministério da Saúde. Secretaria de Atenção à Saúde. Departamento de Atenção Básica. Departamento de Açôes Programáticas Estratégicas. Saúde Mental. Brasília, 2013. (Cadernos de Atenção Básica).

BRASIL. Ministério da Saúde. Secretaria de Atenção à Saúde.Coordenação Geral de Saúde Mental, Álcool e outras drogas. Viramundo: Boletim (In)formativo, em formação e desformatado da RAPS - Rede de Atenção Psicossocial, Brasília, n. 2, p. 17-21, 2014.

BUENO, A. R. Terapia Ocupacional no campo da saúde mental infanto-juvenil: revelando as ações junto aos Centros de Atenção Psicossocial Infanto-juvenil (CAPSi). 2013. 145 f. Dissertação (Mestrado em Terapia Ocupacional)Universidade Federal de São Carlos, São Carlos, 2013. CAVALCANTI, C. M.; JORGE, M. S. B.; SANTOS, D. C. M. Onde está a criança? Desafios e obstáculos ao apoio matricial de crianças com problemas de saúde mental. Physis, Rio de Janeiro, v. 22, n. 1, p. 161-178, 2012. COSTA, J. F. Ordem médica e norma familiar. Rio de Janeiro: Graal, 1983.

COUTO, M. C. V. Novos desafios à reforma psiquiátrica brasileira: necessidade da construção de uma política pública de saúde mental para crianças e adolescentes. In: BRASIL. Ministério da Saúde. Conselho Nacional de Saúde. Caderno de Textos III. Conferência Nacional de Saúde Mental: cuidar sim, excluir não. Brasília, 2001. p. 121-130.

COUTO, M. C. V.; DELGADO, P. G. G. Intersetorialidade: exigência da clínica na atenção psicossocial. In: LAURIDSEN-RIBEIRO, E. P. P.; TANAKA, O. Y. (Org.). Atenção em saúde mental para crianças e adolescentes no SUS. São Paulo: Hucitec, 2010. p. 217-279.

COUTO, M. C. V.; DUARTE, C. S; DELGAdO, P. G. G. A saúde mental infantil na saúde Publica brasileira: situação atual e desafios. Revista Brasileira de Psiquiatria, São Paulo, v. 4, n. 30, p. 390-398, 2008.

CUNHA, C. C.; BOARINI, M. L. O lugar da criança e do adolescente na Reforma Psiquiátrica. Revista Psicologia e Saúde, Campo Grande, v. 3, n. 1, p. 68-78, 2011. Disponível em: <http://www.gpec.ucdb.br/pssa/index.php/ pssa/article/viewFile/83/150>. Acesso em: 30 jul. 2012.

DELFINI, P. S. S.; REIS, A. O. A. Articulação entre serviços públicos de saúde nos cuidados voltados à saúde mental infantojuvenil. Cadernos de Saúde Pública, Rio de Janeiro, v. 28, n. 2, p. 357-366, 2012.

ELIA, L. A rede de atenção na Saúde Mental: articulação entre Caps e ambulatórios. In: BRASIL. Ministério da Saúde. Secretaria de Atenção à Saúde. Caminhos para uma politica de saúde mental infanto-juvenil. Brasília, 2005. p. 49-61.

FERNANDES, A. D. S. A. Cotidiano de adolescentes vinculados a um Centro de Atenção Psicossocial Infantojuvenil (CAPSi): realidade e perspectivas. 2014. 136 f. Dissertação (Mestrado em Terapia Ocupacional)-Universidade Federal de São Carlos, São Carlos, 2014.

HOFFMANN, M. C. C. L.; SANTOS, D. N.; MOTA, E. L. A. Caracterização dos usuários e dos serviços prestados por Centros de Atenção Psicossocial Infanto-Juvenil. Cadernos de Saúde Pública, Rio de Janeiro, v. 24, n. 3, p. 633-642, 2008.

MÂNGIA, E. F.; NICÁCIO, F. Terapia Ocupacional e Saúde Mental: tendências principais e desafios contemporâneos. In: DE CARLO, M. M. R. P.; BARTALOTTI, C. C. (Org.). Terapia Ocupacional no Brasil: tendências e perspectivas. São Paulo: Plexus, 2001. p. 63-80.

OLIVEIRA, M. F. A. P. B. et al. Processos de trabalho e impasses institucionais em Saúde Mental. In: REIS, A. O. A. et al. (Org.). As crianças e os adolescentes dos Centros de Atenção Psicossocial Infantojuvenil. São Paulo: Schoba, 2012. p. 165-179.

ORGANIZAÇÃO MUNDIAL DA SAÚdE - OMS. Organização Pan-Americana de Saúde. Relatório sobre a saúde no mundo. Saúde mental: nova concepção, nova esperança. Suíça: World Health Report, 2001.

PITTA, A. O que é Reabilitação Psicossocial no Brasil, hoje? In: PITTA, A. (Org.). Reabilitação Psicossocial no Brasil. São Paulo: Hucitec, 2001. p. 19 -26.

REIS, A. O. A. et al. Breve história da saúde mental infantojuvenil. In: LAURIDSEN-RIBEIRO, E. P. P.; TANAKA, O. Y. (Org.). Atenção em saúde mental para crianças e adolescentes no SUS. São Paulo: HUCITEC, 2010. p. 109-130.

RIBEIRO, P. R. M. História da saúde mental infantil: a criança brasileira da Colônia à República Velha. Psicologia em Estudo, Maringá, v. 11, n. 1, p. 29-38, 2006. Disponível em: <http://www.scielo.br/scielo.php?script=sci_arttext \&pid=S14133722006000100004\&lng=pt\&nrm=iso $>$. Acesso em: 17 abr. 2012.

RIZZINI, I. Abordagem crítica da institucionalização infanto-juvenill no Brasil. In: BRASIL. Ministério da Saúde. Secretaria de Atenção à Saúde. Departamento de Açóes Programáticas Estratégicas. Caminhos para uma politica de saúde mental infanto-juvenil. Brasília, 2005. p. 31-36.

TAÑO, B. L. Os Centros de Atenção Psicossocial Infantojuvenis (CAPSi) e as práticas de cuidado para as crianças e adolescentes em intenso sofrimento psíquico. 2014. 207 f. Dissertação (Mestrado em Terapia Ocupacional)-Universidade Federal de São Carlos, São Carlos, 2014. 


\section{Contribuição dos Autores}

Ambas autoras foram responsáveis pela concepção, elaboração e revisão do texto.

\section{Notas}

${ }^{1}$ Texto integrante da Dissertação de Mestrado de Bruna Lídia Taño "Os Centros de Atenção Psicossocial Infantojuvenis (CAPSi) e as práticas de cuidado para as populaçôes em sofrimento psíquico intenso”, defendida no Programa de Pós-Graduação em Terapia Ocupacional da Universidade Federal de São Carlos em fevereiro de 2014, de autoria da primeira autora e orientação da segunda autora.

${ }^{2}$ É importante frisar que não se trata de diminuir o sofrimento advindo das situaçôes retratadas acima, mas sim considerar que a proposta inicial dos CAPSi consiste no atendimento preferencial e substancial às crianças e adolescentes gravemente comprometidos em decorrência de sofrimento psíquico intenso, principalmente aqueles posteriormente diagnosticados com autismo, psicoses e esquizofrenia. 